\title{
A prospective study of functional outcome of treatment of supracondylar fracture of femur by locking compression plate
}

\author{
Sathish Kumar $S^{1, *}$, Madan Ballal ${ }^{2}$, T.H. Prakashappa ${ }^{3}$, Vamsinath $\mathbf{P}^{4}$ \\ ${ }^{1,4}$ Junior Resident, ${ }^{2}$ Associate Professor, ${ }^{3} \mathrm{HOD}$, Dept of Orthopaedics, Sanjay Gandhi Institute of Trauma and Orthopaedics, \\ Bangalore, Karnataka, India
}

*Corresponding Author:

Email: satish.hs88@gmail.com

\begin{abstract}
Aim: To evaluate the functional outcome of supracondylar femur fracture treated by locking compression plate.

Materials and Methods: Our study consists of 20 cases of supracondylar femur fracture operated at Sanjay Gandhi institute of trauma and orthopaedics from November 2015 to march 2017.Functional outcome was assessed through Neers scoring system. All the cases in the study were posttraumatic.

Mean duration of follow up was 11 months

Results: There were 7 male patients and female were 13.Average age of the patients was 40.5 years with age ranging from 18 years to 77 years. 14 cases involved the right femur whereas 7 left sided femur fracture occured.

The study included only one case of compound type 1 femur fracture and 19 cases were closed supracondylar femur fractures. The mode of injury was RTA for 12 cases and 8 cases had history of self-fall. Only 3 cases had associated injuries. In patients with associated injuries early rehabilitation were delayed but results were comparable with other cases of the study.

In our study Muller type A3 was the most common fracture presentation which consists of 7 cases followed by 5 type A1 fractures. There were 4 cases of type $\mathrm{C} 1$ fractures, 2 cases of type $\mathrm{C} 3$ fracture and one case in each type A2 and C2 group.

5 cases were operated under MIPPO technique which were extraarticular fractures. Further all fractures which had articular involvement were operated on standard open approach. Average surgical procedure timing was 101.5 minutes in our study.

Most of the patients had excellent postoperative knee flexion with average knee flexion of 119 degrees. Average duration of radiological union was 19.3 weeks and average duration of weight bearing was 20.3 weeks.1 patient in the study had delayed union, 2 cases had a extensor lag of 5 degree while 1 patient had an extensor lag of 10 degrees.

10 cases in the study had fracture union without any complications. Stiffness was present in 7 cases, Knee pain was reported in 3 cases. 1 cases had shortening of $1 \mathrm{~cm}$.Superficial infections were reported in two cases which responded to intravenous antibiotics based on pus culture report. There was no incidence of deep surgical site infection in our study.

In our study there was one case of implant failure requiring revision surgery. The patient had a episode of fall 3 months after primary surgery. Radiograph showed implant failure with varus deformity at the fracture site and no signs of callus formation.
\end{abstract}

Keywords: LCP, Supracondylar femur fracture, Distal femur fracture, Functional outcome.

\section{Introduction}

In the mordernised world due to rapid industralisation and road traffic accidents the incidence of distal femur fractures has increased. Distal femoral fractures mainly arise from two different injury mechanisms. They are often caused by high energy trauma mainly sustained in road traffic accidents. In elderly patients, fracture of distal femur is commonly due to low energy trauma such as fall and extreme osteoporosis represents a particular problem for anchoring the implant. ${ }^{1}$ The conservative management of distal femur fractures were practised in the early part of the century but complications of this modality of treatment such as knee stiffness, limb shortening, angulation, non-union and malunion led to shift of focus to operative plan of management. ${ }^{2,3}$

In the recent years most surgeons agree that distal femur fractures has to be operated to achieve optimal functional outcomes. ${ }^{4}$ As the complexity of fractures needing treatment has changed from simple extraarticular supracondylar types to inter-condylar and metaphyseal comminuted types, there is no single implant ideal to treat all kinds of distal femur fractures.

Elderly patients with severe osteoporosis add further to the difficulties in management of fractures around knee which requires restoration of articular congruency for painless free movements of joint. Loss of stable fixation in osteoporotic bones is of great concern in such elderly patients. ${ }^{1,5,6}$ The LCP is a single beam construct where the strength of its fixation is equal to the sum of all screw-bone interfaces rather than a single screw's axial stiffness or pullout resistance as seen in unlocked plates. Its unique biomechanical function is based on splinting rather than compression resulting in flexible stabilization, avoidance of stress shielding and induction of callus formation. Further when it is applied via a minimally invasive technique, it allows for prompt healing, lower rates of infection and reduced bone resorption as blood supply is preserved. ${ }^{7}$

The purpose of the study is to evaluate the outcomes of treatment of supracondylar femur fractures by open reduction and internal fixation using distal femoral locking compression plate. 


\section{Materials and Methods}

The study was done in the department of Orthopaedics, Sanjay Gandhi Institute of Trauma and Orthopaedics, Bangalore. This study consisted of 20 patients visiting outpatient department, emergency department of the hospital. Patients diagnosed with distal femur fractures were included in the study who were operated during the period from November 2015March 2017. The duration of follow up ranged from 6 months to 15 months. All the fractures in this series were post-traumatic. No pathological fractures and fractures below 18 years of age were included in the study. Fractures were classified with the help of radiographs according to the AO-ASIF classification. Preoperative calculation was done on radiographs to ascertain the size of the plate, accurate size of locking, cortical and cancellous screws after subtraction of the magnification factor. Neers scoring system $^{8}$ was used to evaluate the postoperative surgical outcome.

Relevant history followed by patient or patient's attender and consent for the operative procedure was taken and the distal femoral fractures were treated Locking Compression Plate (LCP).

\section{Results}

Our study consists of 20 cases of supracondylar femur fracture operated at Sanjay Gandhi institute of trauma and orthopaedics from November 2015 to March 2017. Functional outcome was assessed through Neers scoring system. Out of 20 cases there were 7 male patients and female were 13. Average age of the patients was 40.5 years with age ranging from 18 years to 77 years. 14 cases involved the right femur whereas 7 left sided femur fracture occured.

The study included only one case of compound type 1 (Gustillo Anderson) femur fracture and 19 cases were closed supracondylar femur fractures. The mode of injury was RTA for 12 cases and 8 cases had history of self-fall. Only 3 cases had associated injuries. In patients with associated injuries early rehabilitation were delayed but results were comparable with other cases of the study.

In our study Muller type A3 was the most common fracture presentation which consists of 7 cases followed by 5 type A1 fractures. There were 4 cases of type $\mathrm{C} 1$ fractures, 2 cases of type $\mathrm{C} 3$ fracture and one case in each type $\mathrm{A} 2$ and $\mathrm{C} 2$ group.

5 cases were operated under MIPPO technique which were extra articular fractures. Further all fractures which had articular involvement were operated on standard open approach. Average surgical procedure timing was 101.5 minutes in our study

Most of the patients had excellent postoperative knee flexion with average knee flexion of 119 degrees. Average duration of radiological union was 19.3 weeks and average duration of weight bearing was 20.3 weeks. 1 patient in the study had delayed union. 2 cases had a extensor lag of 5 degree while 1 patient had an extensor lag of 10 degrees.

10 cases in the study had fracture union without any complications. Stiffness was present in 7 cases, Knee pain was reported in 3 cases. 1 cases had shortening of $1 \mathrm{~cm}$. Superficial infections were reported in two cases which responded to intravenous antibiotics based on pus culture report. There was no incidence of deep surgical site infection in our study.

In our study there was one case of implant failure requiring revision surgery. The patient had a episode of fall 3 month after primary surgery. Radiograph showed implant failure with varus deformity at the fracture site and no signs of callus formation. The patient underwent revision surgery with removal of implant and revision fixation with a new implant and fibular strut graft. Fracture united 5 months after revision surgery. Functional outcome was poor in this patient.

Table 1: Results of the patients in the study

\begin{tabular}{|c|c|c|c|c|c|c|c|c|c|c|c|}
\hline \multirow[t]{2}{*}{ S.No } & \multirow[t]{2}{*}{ Age } & \multirow[t]{2}{*}{ Sex } & \multirow[t]{2}{*}{ MOI } & \multirow[t]{2}{*}{ Type } & \multirow[t]{2}{*}{ Technique } & \multirow{2}{*}{$\begin{array}{c}\text { OT } \\
\text { Time }\end{array}$} & \multirow{2}{*}{$\begin{array}{c}\text { Union } \\
\text { Time }\end{array}$} & \multirow[t]{2}{*}{ ROM } & Weight & \multirow[t]{2}{*}{ Complication } & \multirow[t]{2}{*}{ Rating } \\
\hline & & & & & & & & & Bearing & & \\
\hline 1 & $55 \mathrm{Y}$ & $\mathrm{F}$ & SF & A1 & MIPO & 60 & 18 & $0-100$ & 20 & ST & G \\
\hline 2 & $34 \mathrm{Y}$ & $\mathrm{M}$ & RTA & A3 & OPEN & 120 & 20 & $0-130$ & 20 & & $E$ \\
\hline 3 & $21 Y$ & $\mathrm{M}$ & RTA & A3 & OPEN & 85 & 17 & $0-130$ & 18 & ST & $\mathrm{G}$ \\
\hline 4 & $75 Y$ & $\mathrm{~F}$ & SF & $\mathrm{A} 2$ & MIPO & 90 & 20 & $0-105$ & 20 & KP & $\mathrm{G}$ \\
\hline 5 & $21 Y$ & $\mathrm{M}$ & RTA & $\mathrm{C} 1$ & OPEN & 100 & 17 & $0-110$ & 18 & ST & $\mathrm{G}$ \\
\hline 6 & $23 \mathrm{Y}$ & $\mathrm{M}$ & RTA & $\mathrm{C} 3$ & OPEN & 105 & 18 & $0-135$ & 18 & & $\mathrm{E}$ \\
\hline 7 & $32 \mathrm{Y}$ & $\mathrm{M}$ & RTA & A3 & OPEN & 135 & 28 & $10-90$ & 30 & ST, IF, SH, DU & $\mathrm{P}$ \\
\hline 8 & $60 \mathrm{Y}$ & $\mathrm{F}$ & $\mathrm{SF}$ & A1 & MIPO & 75 & 20 & $0-130$ & 22 & - & $\mathrm{E}$ \\
\hline 9 & $28 \mathrm{Y}$ & $\mathrm{M}$ & RTA & A3 & OPEN & 120 & 18 & $0-135$ & 19 & _ & $\mathrm{E}$ \\
\hline 10 & $22 \mathrm{Y}$ & $\mathrm{M}$ & RTA & A1 & MIPO & 80 & 16 & $0-120$ & 16 & & $\mathrm{E}$ \\
\hline 11 & $44 \mathrm{Y}$ & $\mathrm{M}$ & RTA & $\mathrm{C} 1$ & OPEN & 115 & 22 & $5-100$ & 23 & ST & $\mathrm{G}$ \\
\hline 12 & $18 Y$ & $\mathrm{M}$ & RTA & C1 & OPEN & 100 & 17 & $0-135$ & 17 & & $\mathrm{E}$ \\
\hline 13 & $58 \mathrm{Y}$ & $\mathrm{F}$ & SF & $\mathrm{C} 1$ & OPEN & 135 & 24 & $0-100$ & 26 & ST, INF, KP & FA \\
\hline 14 & $18 \mathrm{Y}$ & $\mathrm{M}$ & RTA & A1 & MIPO & 70 & 15 & $0-130$ & 17 & NIL & $E$ \\
\hline 15 & $42 \mathrm{Y}$ & $\mathrm{M}$ & RTA & A3 & OPEN & 85 & 18 & $5-95$ & 19 & ST & $\mathrm{G}$ \\
\hline
\end{tabular}




\begin{tabular}{|l|c|c|c|c|c|c|c|c|c|c|c|}
\hline 16 & $55 \mathrm{Y}$ & $\mathrm{F}$ & $\mathrm{SF}$ & $\mathrm{C} 2$ & OPEN & 120 & 22 & $0-130$ & 24 & NIL & E \\
\hline 17 & $77 \mathrm{Y}$ & $\mathrm{F}$ & SF & A3 & OPEN & 105 & 24 & $0-125$ & 24 & KP & G \\
\hline 18 & $55 \mathrm{Y}$ & $\mathrm{M}$ & SF & C3 & OPEN & 125 & 20 & $0-120$ & 21 & INF & G \\
\hline 19 & $20 \mathrm{Y}$ & M & RTA & A1 & OPEN & 90 & 14 & $0-135$ & 14 & NIL & E \\
\hline 20 & $51 Y$ & F & SF & A3 & OPEN & 115 & 18 & $0-130$ & 20 & NIL & E \\
\hline
\end{tabular}

ST-Stiffness, SH-Shortening, KP-Knee pain, IF-Implant failure, INF-Infection

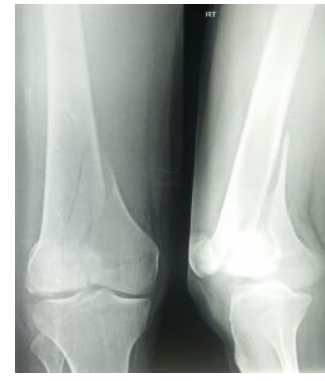

Fig. 1: Pre op x ray

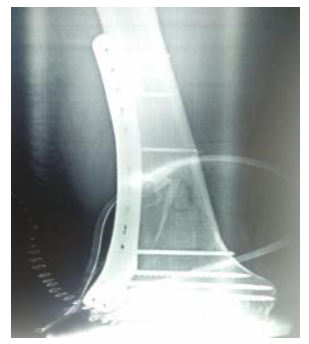

Fig. 2: Immediate post op $x$ ray

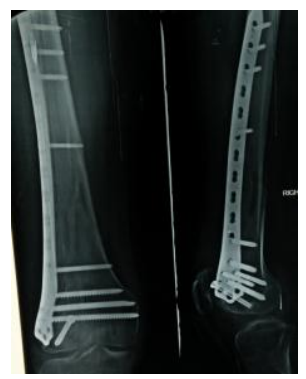

Fig. 3: $4^{\text {th }}$ month post op $x$ ray

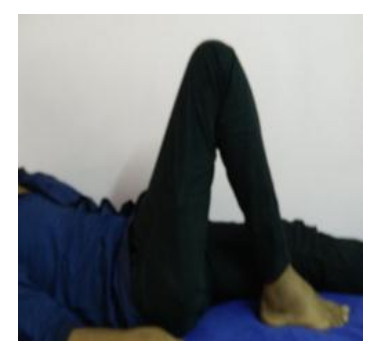

Fig. 4: $4^{\text {th }}$ month post op knee flexion

\section{Discussion}

Locking compression plate is a good fixation implant for supracondylar femur fractures for both intraarticular and extraarticular type. Internal fixation with locking plates creates a toggle free, fixed angle construct. The introduction of plates with the option of locked screws has provided the means to increase the rigidity of fixation in osteoporotic bone or in the presence of periarticular or juxta-articular fractures with a small epiphyseal segment. The implant offers multiple points of fixed-angle contact between the plate and screws in the distal part of femur, theoretically reducing the tendency for varus collapse that is seen with traditional lateral plates. ${ }^{9}$ Advantage of stable fixation even in osteoporotic bone with less chances of implant failure makes it a ideal implant in elderly. Minimal soft tissue dissection is needed when the plate is applied in MIPPO technique leading to better surgical outcome and wound healing. Operative time is reduced due to minimal dissection and blood loss is reduced. Non-requirement of bone graft decreases the morbidity associated with donor site. Patient care is utmost important to avoid surgical infection. There is no much difference in individual fracture type healing and weight bearing site.

There was 1 reported case of implant failure in our study which was due to repeat trauma to the fracture site due to self fall and was not related to implant or technical errors of fixation. Most common complication encountered during the study was knee stiffness. Knee mobilisation should be started on post operative day to achieve optimal knee flexion and avoidance of knee stiffness.

\section{Conclusion}

Locking compression plate (LCP) is a good fixation system for distal end femoral fractures particularly intra-articular type. The device provides good angular stability by its triangular reconstruction principle and thus helps in early mobilization, even in comminuted fractures where other modes of fixation often tend to delay the process of mobilization because of lack of stability. Preferably can be used in osteoporotic fractures were it provides a solution to the age old problems of screw cut out, late collapse, and malalignment since the stability of the construct does not entirely depend on the quality of the bone. Understanding the basic principles of fixation and the appropriate indications for use of LCP in fractures of distal end femur is a must, before its use to prevent technical errors of fixation.

\section{References}

1. Schandelmaier P, Partenheimer A, Koenemann B, et al. Distal femoral fractures and LISS stabilization. Injury. 2001;32 (Suppl 3):SC55-63.

2. Wilson JN. Watson Jone's: Fractures and joint injuries. 6th ed, pg.1003-070, 1982.

3. Charnley John. The closed treatment of common fractures. 3rd ed, Pg.197-204. 
4. Martinet O, Cordey J, Harder Y, et al. The epidemiology of fractures of the distal femur. Injury. 2000;31 (Suppl 3):C62-3.

5. Kregor PJ, Stannard J, Zlowodzki M, et al. Distal femoral fracture fixation utilizing the Less Invasive Stabilization System (L.I.S.S.): the technique and early results. Injury. 2001;32 (Suppl 3):SC32-47.

6. Schutz M, Muller M, Regazzoni P, et al. Use of the Less Invasive Stabilization System (LISS) in patients with distal femoral (AO33) fractures: a prospective multicenter study. Arch Orthop Trauma Surg 2005;125(2):102-8.

7. Kregor PJ, Stannard JA, Zlowodzki M, et al. Treatment of Distal Femur Fractures using the less invasive stabilization system: Surgical experience and early clinical results in 103 fractures. J Orthop Trauma 2004;18(8):509-20.

8. Neer CS, Gratham SA, Shelton ML et al Supracondylar fractures of adult femur. JBJS, Vol. 49-A, pg. 591$613,1967$.

9. Heather V, Theresa H, John S, et al. Failure of LCP condylar plate fixation in the distal part of the femur. J Bone Joint Surg 2006;88-A:846-53. 